\title{
As bases epistemológicas da ecologia da paisagem
}

\section{Epistemological bases of landscape ecology}

\author{
Lia Maris Orth Ritter ${ }^{1}$ e Rosemeri Segecin Moro ${ }^{2}$
}

\author{
${ }^{1}$ Universidade de São Paulo, Escola Superior de Agricultura Luiz de Queiroz. Departamento de Ciências \\ Florestais, 13418-900, Piracicaba SP, Brasil. ${ }^{2}$ Universidade Estadual de Ponta Grossa, Departamento de Biologia \\ Geral, 84030-900, Ponta Grossa PR, Brasil.
}

\begin{abstract}
Landscape began to be cited as a scientific technical term in the nineteenth century. Since then it has been defined according to different philosophical references, where it is possible to see a clear dualism in its meaning. This is a matter of intense debate within the social and natural sciences: the physical geography proposes an understanding of the landscape as an ecological system, whereas the human geography turns to the interpretative vision. There are European and North American roots of the ecological landscape, being the latter more recent (1980s), which is based on ecosystem ecology and spatial modeling/analysis. Its development was favored by the advent of satellite imagery and popularization of personal computers, therefore providing important resources for imaging and geostatistical analyzes. But still, there are different positions to be taken by the researcher working in this area. Metzger (2001) suggests adopting an integrated approach, where the ecological context and human action are considered and managed as mandatory elements in environmental dynamics. Our study aimed to list some of the key concepts of landscape considered by biologists in their research on landscape ecology.
\end{abstract}

Key-words: epistemology, landscape ecology, landscape

\section{INTRODUÇÃO}

Foi na Alemanha que surgiram as primeiras idéias acerca da paisagem sob o ponto de vista da ciência (Passos, 2003). Alexandre Von Humboldt, pioneiro da geografia física moderna e geobotânica, introduziu a discussão da paisagem como termo científico-geográfico no século XIX. Definiu-a como "a totalidade das características de uma região do planeta" (Naveh e Lieberman, 1994). Desde então, o termo passou a ser muito utilizado em Geografia e suas concepções foram se ampliando em consequiência de sua própria análise (Passos, 2003).

A partir do conceito de paisagem proposto por Humboldt e adotado por outros naturalistas, os geógrafos produziram uma reflexão conceitual peculiar. A paisagem tornou-se objeto de estudo da geografia enquanto disciplina acadêmica.

A primeira modificação conceitual veio do biogeógrafo alemão Carl Troll, que em 1939 criou o termo "Ecologia da paisagem" que posteriormente chamou de Geoecologia. Descreveu-a como uma "entidade espacial e visual total" do espaço em que o ser humano vive, integrando geosfera, biosfera e noosfera.

Atualmente diversas ciências abordam a paisagem, fazendo uso de concepções variadas. O termo paisagem ou landscape indica o estudo de características estáticas e dinâmicas de determinadas regiões, considerando aspectos naturais e culturais (Martins et al., 2004).

\section{ABORDAGEM ECOLÓGICA DA PAISAGEM}

A origem da Ecologia da Paisagem na Europa é considerada por Metzger (2001) uma "abordagem geográfica da paisagem", dando bastante ênfase à paisagem denominada cultural. Haveria posteriormente uma retomada, na década de 1980, instaurada por biogeógrafos e ecólogos americanos. Ao adaptar a teoria de biogeografia de ilhas para o planejamento de reservas naturais em

Author for correspondence: 1mritter@usp.br

J. Biotec. Biodivers. v. 3, N.3: pp. 58-61, Aug. 2012 
ambientes continentais, criou-se a "abordagem ecológica da paisagem", que contrariamente à primeira, dá maior ênfase às paisagens naturais, bem como aplicação de conceitos para conservação da diversidade biológica e ao manejo de recursos naturais.

A abordagem americana é baseada na ecologia de ecossistemas e na modelagem e análise espacial. Seu desenvolvimento beneficiou-se do advento das imagens de satélite e das facilidades de tratamento de imagens e de análises geo-estatísticas propiciadas pela popularização dos computadores pessoais. Também foi possível o desenvolvimento de estudos quantitativos de funcionamento ambiental, onde são considerados modelos estatísticos que levam em conta variáveis temporais e espaciais em diversas escalas.

Dá-se nesse tipo de estudo grande ênfase às paisagens naturais ou unidades naturais de paisagem. Visa-se com o trabalho, conservar a diversidade biológica e promover o manejo de recursos naturais (Metzger, 2001). Este tipo de abordagem da paisagem vem se difundindo recentemente no Brasil, tanto em centros de pesquisa quanto em projetos aplicados de ordenamento territorial ou de estudo de impacto ambiental (Metzger et al., 1998), onde a Ecologia da Paisagem é discutida no âmbito da ecologia, geografia e arquitetura, bem como as ferramentas utilizadas nos trabalhos realizados.

\section{INTEGRAÇÃO DE CONCEITOS EM ECOLOGIA DA PAISAGEM}

Em sua obra "Epistemologia Ambiental", Rohde (1996) propõe uma perspectiva de posicionamento nas Ciências Ambientais, prevendo a abordagem da questão a partir da inter e transdisciplinariedade, com diversidade de escalas e enfoques, colocando-se a inter-relação entre Natureza-Sociedade em interfaces e questões, de maneira que devem ser considerados aspectos como: a pressuposição da existência da efetuação humana que é concorrente à natural; a colocação dessa efetuação como um fenômeno contingente; a busca do estabelecimento da reprocessualidade Homem-Natureza; a indicação da necessidade da adoção da amostragem ambiental; a referência aos componentes históricos do conhecimento ambiental. Dessa maneira, as Ciências Ambientais se orientam por questões e não por objetivos disciplinares, assumindo a existência de incertezas, inconclusões e lacunas no conhecimento natural tradicional, que devem ser abordadas como ferramentas, posturas, métodos, abordagens e tematizações inovadoras e originais.

Aproximando-se deste posicionamento, Metzger (2001) sugere uma definição integradora de paisagem, tendo-se a junção da abordagem geográfica, vista pelos olhos do homem, com a abordagem ecológica, pelos olhos das espécies ou comunidades estudadas. Com essa proposição, o autor considera a paisagem como um mosaico heterogêneo formado por unidades interativas, sendo esta heterogeneidade dada por pelo menos um fator, de acordo com um observador e numa determinada escala de observação.

Esta definição evidencia a escala e o nível biológico como dependentes do observador e do objeto de estudo. Assim, possibilita a integração da heterogeneidade espacial e do conceito de escala na análise ecológica, dando uma maior aplicabilidade aos trabalhos voltados à resolução de problemas ambientais.

\section{ENSINO E PESQUISA EM ECOLOGIA DA PAISAGEM NO BRASIL}

Devido a seu caráter recente, a Ecologia da Paisagem ainda passa por uma fase de organização e solidificação de conceitos, sendo necessário testar e refinar sua base conceitual (Turner, 2005). No Brasil, de acordo com Pivello e Metzger (2007), a maioria dos trabalhos produzidos nesta área, descreve padrões espaciais ou modificação destes padrões ao longo do tempo. Temas importantes ainda não estão sendo tratados, principalmente os de cunho mais teórico, como a dinâmica de comunidades sob diferentes escalas da paisagem. Consideram ainda, que é importante não apenas descrever padrões e dinâmicas espaciais, mas procurar entender seus efeitos ecológicos para responder hipóteses científicas de forma quantitativa.

A partir do ano 2000, houve um aumento significativo no número de instituições brasileiras realizando trabalhos em ecologia da paisagem, bem como o de disciplinas a ela relacionadas. Embora a maioria dos trabalhos esteja concentrada nas áreas de ecologia e geografia, merecem destaque as áreas de engenharia florestal, ciências ambientais e desenvolvimento sustentável, agronomia, arquitetura, biologia e botânica (Nanuncio et al., 2007).

Através de um processo lento o ensino e a pesquisa em Ecologia da Paisagem vêm sendo 
modificados, passando de um enfoque predominantemente descritivo para o experimental. Busca-se constantemente a atualização de conceitos e o reforço de bases epistemológicas que embasam esta ciência.

\section{Considerações Finais}

Os estudos em Ecologia da Paisagem permitem que sejam integradas diferentes abordagens relacionadas à análise ambiental. As escalas de trabalho utilizadas são muito variáveis, possibilitando unir diferentes ramos da ciência, especialmente geografia e biologia.

No entanto, o tratamento dado à problemática ambiental e a sua abordagem feita pela geografia, traz à tona uma das principais discussões que marcaram o último quartel de século nos debates dos geógrafos: a dicotomia ou dualidade entre geografia física e geografia humana (Mendonça, 2004). Desta maneira, a escolha da abordagem dos autores norteia-se em função de seus objetivos, embora a Sociedade Internacional de Ecologia de Paisagens lute pela unificação dos conceitos e produção sólida de referenciais teóricos comuns.

A maioria dos biólogos em seus estudos de Ecologia da Paisagem, bem como nas atividades docentes, tem feito uso do posicionamento integrador proposto por (Metzger, 2001). Isto por se acreditar que a visão de amplitude e pluralidade de conceitos é fundamental para o manejo e conservação do ambiente natural e possibilita entender os processos de organização e distribuição dentro do ecossistema. Os estudos que mesclam diferentes abordagens sobre o meio ambiente são relativamente recentes. Este tipo de enfoque propõe o desafio do diálogo entre ciências com bases epistemológicas distintas e paradigmas por vezes conflitantes.

\section{RESUMO}

A paisagem passou a ser citada como um termo técnico científico a partir do século XIX. Desde então recebe definições que a atrelam a referenciais filosóficos diferentes, sendo possível verificar um nítido dualismo no seu significado, motivo de intensos debates no âmbito das ciências sociais e naturais: a geografia física propõe um entendimento da paisagem como um sistema ecológico, a geografia humana volta-se para a visão interpretativa. Tratando-se da abordagem ecológica da paisagem, há uma raiz européia e outra norte americana, sendo que a segunda é mais recente (década de 1980), baseada na ecologia de ecossistemas e na modelagem e análise espacial, tendo seu desenvolvimento favorecido pelo advento das imagens de satélite, popularização dos computadores pessoais propiciando a facilidade para o tratamento de imagens e análises geo-estatísticas. Mas ainda assim, para o trabalho neste âmbito, também há diferentes posicionamentos a serem tomados pelo pesquisador, sendo que Metzger (2001) sugere adotar uma proposta integradora, onde o contexto ecológico e a ação antrópica são considerados e administrados como elementos obrigatórios na dinâmica ambiental. Este estudo teve como objetivo elencar algumas dos principais conceitos de paisagem considerados pelos biólogos em suas pesquisas de ecologia de paisagem.

Palavras-chave: epistemologia, ecologia da paisagem, paisagem

\section{REFERÊNCIAS}

Farina, A. (2000). Landscape Ecology in action. Dordrecht, Kluwer Academic Publishers. 317 p.

Martins, E. S; Reatto, A.; Carvalho Júnior, O. A. E Guimarães, R. F. 2004. Ecologia de Paisagem: Conceitos e Aplicações Potenciais no Brasil. Documentos Técnicos 121. Planaltina, Embrapa Cerrados.

Mendonça, F. (2004). Geografia Sócioambiental. In: Kozel, S e Mendonça, F. Elementos de Epistemologia da Geografia Contemporânea. Curitiba, UFPR, p.121-143

Metzger, J. P.; Pivello, V. E.; Joly, C. A. (1998). Landscape Ecology Approach In The Conservation And Rehabilitation Of Riparian Forest Areas In S.E. Brazil. IN: Salinas Chávez, Eduardo, \& Middleton, John (org). Disponível em: $<$ http://www.brocku.ca/tren/EPI/lebk/ lebk.html>. Acesso em 20 ago. 2011

Metzger, J. P. (2001). O que é ecologia de paisagens? In: Biota Neotropica. 1, 1-9.

Nanuncio, V. M.; Ritter, L. M. O.; Spies, D. S.; Moro, R. S. (2007). A concepção da Ecologia da Paisagem na produção científica da PósGraduação no Brasil. In: Simpósio Paranaense de Pós Graduação em Geografia, Londrina: UEL, 19p.

Naveh, Z. and Lieberman, A. (1994), Landscape Ecology: theory and application. Springer-Verlag, New York, 360p. 
Nucci, J. C. (2007), Origem e desenvolvimento da Ecologia e da Ecologia da Paisagem. Revista Eletrônica Geografar, 2, 77-99.

Passos, M. M. dos (2003), Biogeografia e Paisagem. Maringá [sn], 264p.

Pivello, V. R. e Metzger, J. P. (2007), Diagnóstico da pesquisa em ecologia de paisagens no Brasil (2000-2005). Biota neotropica, 7, 21-29
Rohde, G. M. (1996), Epistemologia Ambiental: uma abordagem filosófico científica sobre a efetuação humana alopoiética. Porto Alegre: EDIPUCRS, 167p.

Troll, C. (1966). Landscape Ecology. Delf: Publ. UNESCO, 23p.

Turner, M. G. (2005). Landscape ecology: what is the state of the science? Annual Review of Ecology, Evolution, and Systematics. 36, 319-344. 